\title{
MEDICALIZAÇÃO DA EDUCAÇÃO E OS SENTIDOS DO NÃO APRENDER DISCURSIVIZADOS NA DOCUMENTAÇÃO PEDAGÓGICA: UM OLHAR PARA O DISCURSO DA ESCOLA
}

\author{
MEDICALIZACIÓN DE LA EDUCACIÓN Y SIGNIFICADO DE NO APRENDIZAJE \\ DISCURSIVIZADO EM LA DOCUMENTACIÓN PEDAGÓGICA: UMA MIRADA AL \\ DISCURSO ESCOLAR
}

\section{MEDICALIZATION OF EDUCATION AND THE MEANINGS OF NOT LEARNING DISCUSSED IN PEDAGOGIAL DOCUMENTATION: A LOOK AT SCHOOL DISCOURSE}

\author{
Claudia Regina Mosca GIROTO ${ }^{1}$ \\ Jaqueline Belga MARQUES ${ }^{2}$ \\ Amanda Trindade GARCIA ${ }^{3}$
}

RESUMO: No campo da educação, há uma rede de explicações medicalizadoras e patologizadoras que buscam justificar o não aprender, sob a qual proliferam doenças do não aprender atribuídas a alunos em fase inicial do processo formal de apropriação da escrita. Com base em tais ideias, o presente estudo objetivou compreender os sentidos sobre o não aprender nos discursos escritos de uma escola de Ensino Fundamental apontada, num município de médio porte do interior paulista, como a que possui o maior número de professores com queixas sobre alunos que não aprendem. A partir de pesquisa documental, o processo de geração e compreensão dos dados aqui considerados se remete especificamente à situação de duas crianças matriculadas em classes de $1^{\circ}$ e $2^{\circ}$ anos, respectivamente. Os resultados, pautados nos enunciados discursivizados pela escola, nessa documentação, indiciaram um processo de assujeitamento dessas crianças do processo de apropriação dessa modalidade de linguagem, bem como a naturalização de sentidos do não aprender constituídos sob tendências medicalizadora e patologizadora dos processos educativos.

PALAVRAS-CHAVE: Medicalização da educação. Doenças do não aprender. Linguagem Escrita.

RESUMEN: En el campo de la educación, hay una red de explicaciones medicalizadoras y patologizadoras que buscan justificar el no aprender, bajo la cual proliferan enfermedades

\footnotetext{
${ }^{1}$ Universidade Estadual Paulista (UNESP), Marília - SP - Brasil. Docente no Programa de Pós-Graduação em Educação (PPGE) e do Departamento de Educação Especial, Faculdade de Filosofia e Ciências (FFC). Docente no Programa de Pós-Graduação em Educação Escolar (PPGEE), Faculdade de Ciências e Letras (FCLAr/UNESP) - Araraquara. Doutora em Educação (UNESP). Projeto CNPq Processo no 406241/2016-3. ORCID: https://orcid.org/0000-0001-6267-8085. E-mail: claudia.mosca@unesp.br

${ }^{2}$ Universidade Estadual Paulista (UNESP), Araraquara - SP - Brasil. Mestre pelo Programa de Pós-graduação em Educação Escolar. Projeto CNPq Processo no 406241/2016-3. ORCID: https://orcid.org/0000-0002-17355276. E-mail: jackchagas@hotmail.com

${ }^{3}$ Universidade Estadual Paulista (UNESP), Marília - SP - Brasil. Mestre pelo Programa de Pós-Graduação em Educação. Projeto CNPq Processo no 406241/2016-3. ORCID: https://orcid.org/0000-0001-7092-7395. E-mail: trindade.amanda@gmail.com
}

RIAEE - Revista Ibero-Americana de Estudos em Educação, Araraquara, v. 15, n. esp. 5, p. 2932-2949, dez. 2020. e-ISSN: 1982-5587 
del no aprender atribuidas a alumnos en fase inicial del proceso formal de apropiación de la escritura. Sobre la base de estas ideas, el presente estudio ha tenido como objetivo comprender los sentidos sobre el no aprender discursivizados en la documentación pedagógica utilizada en una escuela de Enseñanza Primaria designada, en un municipio de mediano porte del interior paulista, como la que tiene el mayor número de profesores con quejas sobre alumnos que no aprenden. A partir de la investigación documental, el proceso de generación y comprensión de los datos aquí considerados se remite especificamente a la situación de dos niños matriculados en clases de $1^{\circ}$ y $2^{\circ}$ años, respectivamente.Los resultados, pautados en los enunciados discursivizados por la escuela, en esa documentación, indicaron un proceso de asunción de esos niños del proceso de apropiación de esa modalidad de lenguaje, así como la naturalización de sentidos del no aprender constituidos bajo tendencias medicalizadora y patologízadora de los procesos educativos

PALABRAS CLAVE: Medicalización de la educación. Enfermedades del no aprender. Lenguaje escrito.

ABSTRACT: In the field of education, there is a network of medicalizing and pathologizing explanations that seek to justify not learning, under which proliferate diseases of not learning attributed to students in the early stages of the formal process of appropriation of writing. Based on such ideas, this study aimed to understand the meanings of not learning discursivized in the pedagogical documentation used in a school of Elementary School pointed out, in a medium-sized city in the interior of São Paulo, like the one with the largest number of teachers with complaints about students who do not learn. From documentary research, the process of generation and understanding of the data considered here refers specifically to the situation of two children enrolled in classes of 1 st and 2nd years, respectively. The results, based on the discursivized statements by the school, in this documentation, indicated a process of assumption 2 a of these children of the process of appropriation of this type of language, as well as the naturalization of meanings of not learning constituted under tendencies medicalizing and pathologizing of the educational processes.

KEYWORDS: Medicalization of education. Diseases of not learning. Written language.

\section{Introdução}

O aprendizado da escrita compreendida como atividade cultural complexa se dá no uso da linguagem presente na vida, na interação entre os sujeitos inseridos nas mais diversas práticas sociais, tendo em vista que o sujeito se constitui na relação social com o outro, em um movimento dialético e dialógico permanente. Sendo viva e dialógica, produto da interação humana e, portanto, constitutiva do sujeito, a linguagem escrita, como prática social e discursiva, pressupõe alguém que diz algo a alguém, por meio de enunciados constitutivamente dialógicos, cuja historicidade refrata e é refratada nas condições de sua produção (GERALDI, 2013). O outro, como constitutivo do sujeito, assume relevância 
determinante na constituição da consciência e na relação do sujeito com sua realidade, com o mundo da vida (BAKHTIN, 2011; VIGOTSKI, 2012; VOLÓCHINOV, 2017).

Vigotski (2007; 2012), ao buscar compreender de que maneira as experiências sociais formulam ou constituem a mente humana, a aprendizagem e o desenvolvimento, e ao apontar a importância do outro na constituição do sujeito, enfatiza que o processo de aprendizagem se realiza através da interação entre a criança, o meio e seus parceiros, num processo de colaboração entre as pessoas. Neste viés é possível entender que a formação humana do aluno não é resultado apenas das experiências escolares, mas de várias vozes e sujeitos que perpassam suas relações.

Sob essa compreensão, a aprendizagem não tem um caráter individual, evolutivo ou externamente controlável, pois, ao indicar que o aprendizado mobiliza processos internos e novas apropriações por meio da interação com outras pessoas, Vigotski (2007, p. 118) afirma que aprendizagem e desenvolvimento da criança, mesmo que diretamente ligados, não se produzem de maneira paralela, do mesmo modo que o desenvolvimento nunca acompanha a aprendizagem escolar, bem como a apropriação de conhecimentos não é linear, uma vez que,

O aprendizado desperta vários processos internos de desenvolvimento que são capazes de operar somente quando a criança interage com pessoas em seu ambiente e quando em cooperação com seus companheiros. Uma vez internalizados, esses processos tornam-se parte das aquisições do desenvolvimento independente da criança.

Neste sentido, a ação educativa deve focar o que Vigotski (2012) denomina de zona de desenvolvimento próximo, que se configura pelo que a criança ainda não é capaz de fazer de maneira independente, mas pode fazer com a ajuda de outros parceiros mais experientes. Ao se ocupar de uma atividade que, inicialmente, extrapola suas possibilidades de realização autônoma, sob mediação de tais parceiros, a criança se prepara para, num futuro próximo, realizá-la de forma independente. Dessa perspectiva, toda tentativa inicialmente e aparentemente sem solução de algo tem, em si, a possibilidade, posterior, de acerto.

A compreensão da escrita como atividade cultural complexa possibilita pensar a escola como lugar de apropriação da cultura historicamente criada pelo homem, por meio de vivências e contatos com diferentes tipos de conhecimentos que, sob mediação, promovam o conhecimento elaborado, constituído no/pelo uso social da linguagem presente na vida, em detrimento do ensino mecânico que prevê, predominantemente, atividades monológicas de treino, repetição e memorização, desprovidas do dialogismo fundante e necessário à apropriação dessa modalidade de linguagem. 
Semelhantemente, o trabalho educativo precisa ser compreendido como "[...] o ato de produzir, direta e intencionalmente em cada indivíduo singular, a humanidade que é produzida histórica e coletivamente pelo conjunto dos homens" (SAVIANI, 1991, p. 19). O trabalho do educador demanda cientificidade, pois não é de senso comum. Precisa possibilitar à criança a atividade sobre a escrita, ao considerar a complexidade do conhecimento elaborado e as singularidades inerentes aos distintos modos de apropriação dessa modalidade de linguagem. Atividade é aqui entendida como “[...] o agir provocado por uma necessidade que orienta e regula" que, relacionada à apropriação da escrita, demanda a proposição da atividade como processo "[...] que cria uma necessidade no aluno, a fim de que ele busque um objeto que satisfaça essa necessidade" (GARCIA, 2019, p. 25).

Por sua vez, a criança precisa ser considerada como um ser histórico e cultural, que apreende sua humanidade por meio de sua atividade no mundo (VIGOTSKI, 2007). Dessa perspectiva, a criança é sujeito produtor de cultura, uma vez que "[...] o sujeito não é coisa, pois ele fala, ele tem consciência que se alarga para receber outra consciência que também se alarga. Sem a linguagem do homem o humano do homem não se constitui”. Portanto, “[...] linguagem é a mediação entre um outro e um Eu, e linguagem é a atividade constitutiva; o diálogo é o lugar construtor” (MIOTELLO, 2012, p. 153).

Infelizmente, a escola tem sido frequentemente compreendida como mero local de transmissão de informações, com pouco espaço para a materialização do dialogismo característico e necessário à apropriação da escrita, assim como seus profissionais, em grande medida, têm entendido o trabalho educativo sob um caráter tecnicista e monológico, no qual a criança assume um papel passivo, que pouco oportuniza o pensar e o agir sobre/na/com a escrita, submetida a um processo de individualização da responsabilização tanto pelo aprender, quanto pelo não aprender. Ainda, predominam atividades mecanicistas, esvaziadas de sentido, com enfoque excessivo no mero ensino de letras e no domínio de habilidades motoras, fonético/fonológicas e/ou auditivas, em detrimento da necessidade de compreensão da escrita como processo interativo e discursivo, cujas condições de acesso, produção e apropriação encontram-se atreladas a determinantes históricos e coletivos (VIGOTSKI, 2012; VOLÓCHINOV, 2017).

Essa situação tem se constituído em terreno fértil para que a escola se organize alinhada a uma rede de explicações que buscam justificar o não aprender, recorrentemente sob o viés do fracasso escolar. O que tem levado a uma maior discursivização sobre as crianças e o não aprender respaldada por um processo de assujeitamento da criança na apropriação dessa modalidade de linguagem. Essa discursivização, tal como proposta por Giroto, Araújo e Vitta 
(2019, p. 808), é aqui compreendida como o "[...] o processo de construção discursiva carregada de valores sociais, históricos e ideológicos refratados nos/pelos discursos", no caso, que circulam na escola sobre o não aprender, que desconsideram o caráter heterogêneo do alunado matriculado nos sistemas educacionais e as singularidades que constituem os distintos modos de apropriação dessa modalidade de linguagem.

Acerca dessa discursivização nos interessa considerar, particularmente, dois aspectos:

- a naturalização, decorrente dessa discursivização, da constituição de sentidos sobre o não aprender, a partir das tendências medicalizadora e patologizadora dos processos educativos, que promovem, no interior da escola, a proliferação de doentes e doenças do não aprender; e

- a compreensão equivocada sobre a documentação pedagógica, entendida como mero registro de informações sobre o alunado, em vez de ser valorizada como lugar de constituição e circulação da memória educativa, portanto de natureza dialógica, ao contemplar a multiplicidade de vozes que são discursivizadas e que discursivizam sobre a criança.

A naturalização da constituição de sentidos sobre o não aprender, sob a tendência medicalizadora, ocorre na medida em que questões coletivas, de origem social, política, econômica, cultural, linguística são reduzidas a aspectos orgânicos/individuais, consequentemente, deslocados para o campo médico, caracterizando um processo de medicalização da educação (COLLARES; MOYSÉS, 2010; 2013). Tal processo, em muito proveniente da difusão do saber médico no tecido social, encontra-se atrelado ao reducionismo do controle técnico sobre a vida e alinhado a um modelo idealizado de saúde, fundado num conceito padronizado de normalidade, ao assumir caráter normatizador e homogeneizador dos distintos modos de ser e agir, de aprender e se comportar (GUARRIDO, 2010; FREITAS; BAPTISTA, 2019).

Por sua vez, a tendência patologizadora amplifica a compreensão reducionista sobre o não aprender, principalmente por parte de áreas afins à medicina, ao se caracterizarem como efeito da ressonância do reducionismo técnico-científico no campo educacional e, consequentemente, promoverem o processo de patologização da educação que, sob um sentido mais amplo, não vinculado a uma área específica de conhecimento, se refere à atribuição de status de doente a sujeitos que manifestam singularidades que os distanciam dos padrões idealizados de aprendizagem, ao ponto de ocorrências previstas no processo de escolarização tornarem-se critérios preditivos e/ou manifestações de doenças do não aprender. 
Ao mesmo tempo que o aprender é reduzido a modelos idealizados, circunstanciados a expectativas normativas (na verdade inalcançáveis), o não aprender, sob o viés predominantemente biológico e tecnicista, passa a ser concebido como desvio da norma idealizada. Ao estender tal compreensão ao campo educacional, uma vez que tais expectativas se encontram idealizadas, é esperado que sejam cumpridas, sendo conferidas às mesmas a condição de normas. Sob esse viés, ao não aprender resta, então, o lugar do fracasso escolar e da inadequação ao processo de escolarização.

Tal situação constitui-se em terreno fértil para que o aprender e, consequentemente, o não aprender sejam encarados à margem de seus múltiplos determinantes, os quais acabam silenciados e/ou apagados frente ao processo de estigmatização de sujeitos que deixam de ser compreendidos em suas complexidades e especificidades e em relação à dinâmica sociocultural que vivenciam em determinada época e lugar.

Compreender o não aprender como sinônimo de fracasso escolar, desatrelado dos determinantes socioeconômicos, político-ideológico, o configura como abstração, circunscrito a aspectos meramente individuais, o que o distancia da compreensão de que tanto sua origem quanto solução residem na estreita relação com as desigualdades sociais e desiguais condições de trabalho às quais se encontra submetida a maior parte da população brasileira (PATTO, 2000).

Sob os processos de: normalização, aqui compreendido como simplificação dos distintos modos de ser e agir no mundo; homogeneização, como resultante de tal simplificação, a partir do apagamento das singularidades constitutivas; e das expectativas normativas para se alcançar tal homogeneização têm assumido expressiva importância as características preditivas (profetizadoras) alinhadas e/ou decorrentes de tais processos, frequentemente expressas nos documentos que trazem os dados de alunos tidos como os que não aprendem no ambiente escolar.

Acrescentamos aqui que os documentos de maneira isolada não configuram uma documentação pedagógica, ou seja, não trazem a potência de tornar "[...] visíveis os rastros de cada pessoa, de cada grupo, de cada família em sua passagem pela escola" (SOLÁ, 2007, p. 40).

Os documentos pedagógicos podem ser utilizados para reflexão e análise dos processos educativos para evidenciar “[...] os modos como as crianças constroem conhecimentos, de fortalecer uma identidade própria da educação das crianças pequenas, da construção da qualidade dos contextos educativos" (PINAZZA; FOCHI, 2018, p. 14). 
Entretanto, esses materiais têm sido frequentemente reduzidos a documentos sob a denominação das expressões prontuário e/ou laudo, cujo uso no ambiente escolar pode ser tomado como um exemplo da subjetivação do discurso médico pela educação, nos quais figuram, além de informações médicas e cópias de exames, registros vagos sobre trajetórias educacionais, muitas vezes apoiados no senso comum, cujas narrativas abordam, invariavelmente, dificuldades apresentadas pelas crianças.

A documentação pedagógica deveria possibilitar uma escola de narrações diversas, de narrações incertas, em que os roteiros são escritos a partir das vozes nas relações de cada um. Roteiros que se vivem construindo histórias assentados em contextos participativos (SOLÁ, 2007).

Se considerarmos que o trabalho do professor demanda trabalho científico, a partir de seus estudos e observações, a documentação pedagógica que acontece no contexto do ensino fundamental não é caracterizada como tal, pois não contempla a construção da memória educativa. Ao reduzir o processo de discursivização a meros registros, não potencializa essa prática como possibilidade de acolhimento das subjetividades e do diálogo cotidiano acerca das práticas pedagógicas empreendidas, particularmente em relação às crianças consideradas como as que não aprendem e apresentam doenças do não aprender.

Sob a premissa de que a discursivização que naturaliza os sentidos medicalizados e patologizados do não aprender, materializados em prontuários e laudos, a partir dos equívocos e reducionismos sob os quais a documentação pedagógica tem sido compreendida pela escola e seus profissionais contribui para a promoção de uma demanda para os serviços da saúde produzida sob o discurso da anormalidade, um questionamento se faz necessário: quais sentidos do não aprender circulam nesses documentos produzidos na escola, suas implicações e consequências?

Frente a tal premissa e questionamento, o presente estudo objetivou compreender os sentidos sobre o não aprender presentes nos discursos escritos de uma escola de Ensino Fundamental apontada, num município do interior paulista, como a que possui o maior número de professores com queixas sobre alunos que não aprendem, que remetem especificamente, no presente artigo, à situação de duas crianças matriculadas em classes de $1^{\circ}$ e $2^{\circ}$ anos, respectivamente, em início da apropriação formal da escrita. 


\section{Percurso metodológico}

O percurso metodológico compreendeu uma pesquisa documental, na qual foi utilizada, como fonte de dados, os discursos escritos em documentos da escola. A opção por esses dados ocorreu por considerarmos que os registros escolares têm uma grande importância na produção de subjetividades, pois podem ser caracterizados como práticas que atualizam os discursos e produzem modos de ser e aprender do aluno, ao mesmo tempo em que revelam a cultura escolar sob a qual os alunos e seus distintos modos de apropriação de conhecimentos são compreendidos (MARQUES, 2018).

Partimos da indicação anterior de uma Diretoria de Ensino que identificou, num município do interior paulista, a escola com maior número de queixas, por parte de seus professores, de crianças que não aprendem. Em seguida, obtivemos a indicação, por parte do gestor dessa escola, dos professores que atuavam nos anos iniciais do Ensino Fundamental que apresentavam o maior número de queixas dessa natureza. Foram aqui consideradas duas professoras que, por sua vez, identificaram, em suas respectivas salas de aula, a criança com maior dificuldade para aprender. Não foram considerados alunos com laudo médico que os vinculasse a doenças preexistentes.

Desse modo, tivemos acesso aos documentos de duas crianças, doravante apresentadas como: Julia, com seis anos de idade e matriculada no $1^{\mathrm{o}}$ ano do Ensino Fundamental I, e Amanda, com oito anos, no $2^{\circ}$ ano. Optamos por esse período de escolarização, pois o compreendemos como período crítico, quando as crianças são iniciadas no processo formal sistematizado de apropriação da linguagem escrita, no qual, geralmente, aparecem ou são anunciados, mais frequentemente, os rótulos do não aprender (GIROTO; ARAÚJO; VITTA, 2019). Os dados aqui apesentados integram pesquisa aprovada por Comitê de Ética, sob o processo $\mathrm{n}^{\mathrm{o}} 64007416.3 .0000 .5400$.

A geração de dados se deu a partir de todos os tipos de documentos identificados equivocadamente pela gestão escolar como documentação pedagógica dessas crianças, composta por prontuário, laudos, exames e encaminhamentos, bem como utilizamos um roteiro, com vistas à sistematização desses dados, que incluiu: história escolar pregressa e atual da criança; queixas anteriores e atuais de professores, informações de natureza clínica (exames, laudos, medicação, encaminhamentos); ações da escola voltadas a práticas pedagógicas empreendidas visando auxiliar a criança no processo de apropriação da escrita; concepções explícitas e/ou implícitas sobre escrita, criança, escola, trabalho educativo, papel 
do professor. $\mathrm{O}$ acesso à referida documentação ocorreu na própria escola, em horário previamente acordado com o gestor escolar.

Para a compreensão dos dados consideramos os enunciados escritos sobre essas crianças como constitutivos do discurso da escola, uma vez que são, recorrentemente, legitimados, institucionalmente, como os dizeres sobre essas crianças e seus distintos modos de apropriação da escrita, utilizados em reuniões entre os profissionais, com os pais, em justificativas de encaminhamentos e, por vezes, com as próprias crianças.

Desse ponto de vista, na análise buscamos apreender os sentidos do não aprender explícita e/ou implicitamente refratados no/pelo discurso da escola que orbitam sobre Júlia e Amanda, compreendendo que é necessário levarmos em conta os valores que as palavras carregam, pois “[...] a palavra está sempre carregada de um conteúdo ou de um sentido ideológico ou vivencial" (VOLÓCHINOV, 2017, p. 99). Esse discurso foi valorizado, portanto, não apenas como simples registro textual, dado que foi constituído nas relações instauradas antes e durante sua produção, pois os processos de significação não surgem por uma única voz, mas são configurados a partir de diferentes vozes, sob diferentes pontos de vista, e é justamente por essa condição discursiva que as palavras se mostram, inevitavelmente, em uma luta de vozes.

\section{Resultados e discussão}

A apresentação e discussão ora empreendida resultou dos enunciados tomados como constitutivos do discurso da escola e como indícios reveladores: do assujeitamento ao qual Júlia e Amanda se encontram submetidas, em seu processo de apropriação formal da escrita; e da naturalização dos sentidos do não aprender que orbitam sobre elas, discursivizados sob as tendências medicalizadora e patologizadora.

\section{Júlia: entre a invisibilidade em sala de aula e o assujeitamento dos/nos processos educativos}

Os registros escritos gerados pela escola são atravessados por discursos produtores de saberes sobre as crianças, seus comportamentos, suas capacidades e suas dificuldades. Algumas vezes, esses discursos são explícitos e outras vezes implícitos.

Por isso, a análise desses discursos escritos constituiu um desafio, pois buscamos emergir as múltiplas vozes e também os silêncios, que aqui, se referem à escola assumir ou não seu ato responsável, sua responsabilização como posicionamento frente à condição 
enfrentada por essas crianças, apontadas por seus professores como as que não aprendem na escola. Tentar entender como as subjetividades têm sido construídas gera uma prática de reconstrução, num movimento de compreensão que extrapola os registros escritos em si, pois refratam também, dentre outros aspectos, as concepções de escrita, de escola, de trabalho educativo, de criança e do papel do professor na mediação da apropriação de conhecimentos.

De início, é necessário ressaltarmos o equívoco de como a documentação pedagógica é compreendida pela escola, na medida em que tal documentação se refere ao prontuário da criança que reúne uma ficha de matrícula, o relatório do professor registrado numa ficha de desenvolvimento escolar, exames e/ou laudos e encaminhamentos, utilizados de forma muito semelhante aos serviços de saúde, com caráter mais prescritivo/informativo e, invariavelmente, desarticulada a cada ano de registros, a depender do tempo de escolarização. A ficha de matrícula contempla dados pessoais da criança e não congrega elementos suficientes que possibilitem conhecer sua história de relação com a escrita, pois reúne dados que se aproximam muito de uma anamnese clínica, desde a fase gestacional até o momento de ingresso na escola. Na ficha de desenvolvimento escolar há espaço sobre o relato acerca de dificuldades apresentadas pela criança, mas não há lugar para o professor relatar o que a criança é capaz de realizar, seus avanços, a atividade sobre/na/com a escrita, em si.

Cristofari (2014, p. 113), ao apontar a importância dos registros escolares como lócus dialógico para reflexão e interlocução, menciona que, “A escola possui uma prática histórica que consiste em elaborar registros escritos, que são atravessados por discursos produtores de saberes sobre os alunos". Desse ponto de vista, é possível considerar que, tanto os tipos de documentos quanto as informações valorizadas no discurso da escola, sobre as crianças aqui consideradas, são reveladores de que essa documentação não é utilizada como objeto de reflexão e espaço de interlocução.

No prontuário de Júlia há poucas informações, pois ainda não existem registros do ano corrente $\left(1^{\mathrm{o}}\right.$ ano), por ocasião da realização da pesquisa, apenas do ano anterior, quando estudava no Pré II. A professora do Pré II registrou apenas: “[...] aluna pouco participativa na classe, tímida, faltas em excesso", estas justificadas por problemas de saúde, sem nenhuma informação adicional que remeta a qualquer comprometimento de natureza orgânica e/ou qualquer encaminhamento e utilização de medicação. O relato prossegue explicitando que, "[...] apresenta pouco avanço no desenvolvimento da aprendizagem, pensamento é pouco criativo" e conclui com "[...] hipótese de escrita pré-silábica”.

O que nos chamou a atenção é que essa criança se encontra em início do processo formal de apropriação da escrita e tão precocemente é compreendida como uma criança que 
não aprende, antes mesmo de mostrar o que já sabe e o que pode aprender. A narrativa sobre sua trajetória escolar é pobre e esvaziada de elementos que possam subsidiar tal compreensão, uma vez que consta apenas que cursou o Pré II anteriormente ao ingresso nessa escola. Ainda em início do processo formal de apropriação da escrita, Júlia parece já submetida aos processos de individualização da responsabilização tanto pelo aprender, quanto pelo não aprender, bem como de homogeneização de modos de ser e agir, uma vez que as características individuais mencionadas provavelmente ganharam relevância por divergirem do modelo idealizado de aluno.

Individualização no sentido de que, associadas à desmotivação para participação nas atividades de sala de aula, suas características individuais ganham relevância no discurso da escola, sendo indiciadas, ainda que implicitamente, como causas prováveis para tal desmotivação, uma vez que é discursivizada como tímida e pouco participativa. Responsabilização porque tais características parecem já carregadas da culpabilização a ela atribuída no/pelo discurso da escola, pois não correspondem às expectativas de sua professora, ao gerarem "[...] pouco avanço no desenvolvimento da aprendizagem". Homogeneização na medida em que, em articulação com os processos anteriormente mencionados, já se encontra classificada sob indícios da compreensão de apropriação da escrita sob a qual vigora a ideia de que todos aprendem tudo, ao mesmo tempo e do mesmo modo (GIROTO; ARAÚJO; VITTA, 2019; FREITAS; BAPTISTA, 2019).

Não são indiciados aspectos favoráveis sobre Júlia, em seu percurso na escola, bem como não há qualquer menção às suas condições de vida, quer socioeconômicas, familiares, culturais. Para a escola parece não interessar saber quem é Júlia! De onde vem? Quais referências socioculturais traz consigo? Ora, se a criança precisa ser compreendida como produtora de cultura e considerando que a aprendizagem impulsiona o desenvolvimento, é preciso considerar que o aprendizado da criança não acontece a partir da entrada da criança na escola, a produção de conhecimento e construção de sua história se inicia com o seu nascimento (VIGOTSKI, 2007; 2012).

No caso de Júlia, o discurso da escola parece revelar que isso não é levado em consideração, como se Júlia só existisse a partir de sua entrada na escola. O que Júlia tem a dizer? Tem razões para isso? Tem escuta? O trabalho com a escrita, em sala de aula, implica que, para escrever, a criança precisa ter o que, porque e para quem dizer, bem como estratégias que possibilitem constituição e compartilhamento de sentidos, viabilizadas pela ampliação da inserção da criança na cultura e nas práticas educativas (GERALDI, 2013). 
Tais indícios nos levam a considerar que Júlia tem sido compreendida à margem dos processos educativos, sob a condição de assujeitamento do processo de apropriação da escrita. Se encontra apenas no $1^{\circ}$ ano e a escola continua a manter e repetir o discurso de pouco avanço na aprendizagem da escrita, uma vez que foi apontada pela professora do Pré II como uma criança que não aprende. Estigmatizada como incapaz de aprender, parece não ter havido, até o momento, esforço, por parte da escola, em refletir e enfrentar a desmotivação aparentemente apresentada por essa criança na sala de aula.

O trabalho educativo impõe considerar seu caráter científico, não da perspectiva meramente tecnicista, mas sob a visão de que é necessário um fazer intencional do educador para que as aprendizagens aconteçam por meio das atividades propostas articuladas na/pela interação com os produtos da cultura. Neste sentido, o caminho de aprendizagem oferecido pela escola, muitas vezes, não é atrativo para algumas crianças, que necessitam de estratégias de ensino diferentes. Dessa maneira, inicia-se um processo de não aprendizagem, sendo crucial, portanto, que qualquer aprendizagem considere o interesse dos alunos (VIGOTSKI, 2010).

\section{Amanda: das tentativas de silenciamento à naturalização de explicações medicalizadoras e patologizadoras do não aprender}

Amanda, em sua relação com a escrita, é discursivizada, em seu percurso, no Pré I, como: "[...] aluna agressiva, mal-humorada, não se relaciona com os colegas, não aceita regras, se recusa a fazer as atividades propostas e a usar óculos de grau, faltas constantes". Nos anos subsequentes esses enunciados se repetem, tendo sido acrescentado, no Pré II, que "[...] reconhece apenas seu nome e poucas letras do alfabeto, apenas cores primárias e números até 3 ". Nesse mesmo ano foi encaminhada e atendida por fonoaudióloga e psicóloga num programa justificado pelo acolhimento a crianças com dificuldades para aprender.

Nos relatórios dessas profissionais, anexados ao prontuário, a fonoaudióloga enunciou que Amanda participa de "[...] projeto de fonação, apresenta problemas de comportamento, não respeita regras e resiste em realizar as atividades propostas”, assim como a psicóloga afirmou que a criança possui "[...] dificuldades de relacionamento com seus pares, é agressiva, não consegue lidar com emoções, portanto requer avaliações médicas e a família necessita de orientação”. Em relação aos problemas de fonação, a fonoaudióloga não os caracterizou e, quanto às dificuldades de relacionamento, a psicóloga não apresentou 
considerações que nos possibilitasse entender tal avaliação, tendo em vista que apenas reforçou o que a escola já discursivizava sobre Amanda.

Posteriormente, no $1^{\mathrm{o}}$ ano, foi relatado que Amanda recebeu reforço escolar duas vezes por semana, no mesmo período das aulas, sendo retirada da sala de aula para tal. As queixas comportamentais se repetiram, acrescidas de "[...] não reconhece todas as letras do alfabeto, não faz cópias, não consegue escrever e ler sozinha”. Nesse período foi encaminhada para avaliação com neurologista, pediatra, oftalmologista e continuidade da terapia psicológica, porém, não encontramos informações que justificassem esses encaminhamentos, tampouco se foram efetivados. No $2^{\circ}$ ano ainda não constava nenhum registro.

A questão comportamental apareceu recorrentemente no discurso da escola sobre Amanda, atrelada à busca por explicações do campo médico/clínico. Assim como foram recorrentes os enunciados vinculados à relação entre aluno e professor, aluno e profissional de saúde. A indisciplina pareceu, então, indiciada tanto pelos professores, quanto profissionais de saúde atrelada ao não aprender, associada às expectativas da escola de correspondência a um padrão de homogeneização dos modos de ser e agir, possivelmente subjacentes a padrões de normalidade que, embora não expressos diretamente, são desvelados pela busca incessante por explicações medicalizadoras e patologizadoras que justifiquem tanto o não se comportar, quanto o não aprender. Assim como a utilização de expressões oriundas do campo médico são subjetivadas pela escola, a exemplo das denominações prontuário e laudo, que compõem o que a escola compreende como documentação pedagógica. Os sentidos sobre o não aprender parecem refratar e serem refratados como produtores da condição de anormalidade.

De acordo com Freitas e Baptista (2019, p. 800), “[...] o impacto do diagnóstico é impregnante e tem efeitos múltiplos com potencial para produzir o sofrimento do sujeito". Neste sentido, "[...] distanciar nosso olhar do "transtorno" vai nos permitir olhar para o sujeito encarnado, datado, se construindo em relação" (p. 795).

Contrariamente a isso, a escola, como instituição que se configura como elemento da formação da subjetividade, acaba criando ações pedagógicas dirigidas apenas para produção de indivíduos normalizados e, consequentemente, rotulados e em condição de assujeitamento (COLLARES; MOYSÉS, 2010; 2013).

Garcia (2019) atribui a essa situação, dentre outros aspectos, a necessidade de a escola cumprir a alfabetização até o final do $3^{\circ}$ ano do Ensino Fundamental, o que, consequentemente, gera a preocupação em acelerar o processo de apropriação da escrita para que a escola cumpra a legislação. Entretanto, essa aceleração não acompanha as 
particularidades de cada criança e aquela que não corresponde à aprendizagem imposta acaba sendo rotulada como doente, desatenta, agitada, no caso de Amanda, agressiva e malhumorada, características que assumem importância no discurso da escola sob o estatuto de rótulos.

Marques (2018) assevera que o ambiente escolar é grande produtor de rótulos. As crianças são avaliadas a todo momento e são enquadradas por diversas classificações. $O$ discurso da escola classifica, então, de maneira positiva ou negativa.

Também merece destaque o rol de atividades escolares mencionadas como não atendidas por Amanda, indiciando uma perspectiva mecanicista de concepção e atuação com a escrita. Esvaziadas de sentido, essas atividades pouco oportunizam à criança condições de interação e interlocução, bem como sua atuação na/com/sobre essa modalidade de linguagem.

O que deveria ser objeto de reflexão e mudanças das práticas pedagógicas leva à estigmatização de crianças inicialmente sadias, que incorporam o rótulo, sentem-se doentes, agem como doentes. Tornam-se doentes. Compromete-se sua autoestima, seu autoconceito e aí, sim, reduzem-se suas chances de aprender (COLLARES; MOYSÉS, 2010; 2013).

Assim como ocorreu com Júlia, na documentação de Amanda não há indícios de diálogo com a família. Especificamente é feita referência à necessidade de orientações, por parte da psicóloga, porém não são mencionados os motivos que, aparentemente, motivam tal necessidade. Depreende-se, da referida documentação que, muito possivelmente, tais orientações estejam vinculadas aos aspectos comportamentais, frente ao fato de esses aspectos ganharem tamanha relevância no discurso escolar sobre essa criança. Em que medida Amanda já possui consciência sobre o modo como é discursivizada pela escola e seus professores? O que é falado sobre e para Amanda nesse contexto medicalizador e patologizador?

Volóchinov (2017) esclarece que em todo enunciado pode-se perceber as palavras do outro ocultas ou semiocultas. O enunciado se coloca como um fenômeno complexo, se analisado em sua relação dialógica entre o autor (locutor) e os outros enunciados. Se coloca como uma resposta a enunciados anteriores dentro de uma dada esfera, refutando, confirmando, completando, baseando-se nestes outros que também o constituem, em uma cadeia de sentidos e de comunicação que está presente na linguagem.

É possível supor que Amanda se encontra em sofrimento, não encontrando escuta, em seu percurso escolar, dada a persistência desse modo de agir e a condição de assujeitamento à qual está submetida. Expropriada das práticas educativas, ao não se encaixar no modelo idealizado de aluno obediente às normas, parece resistir à lógica normativa. $\mathrm{O}$ que diz o comportamento de Amanda? 
Vygotsky (2010) refere o sentido como a junção de todos os eventos psicológicos que a palavra desperta em nossa consciência. Portanto, o sentido configura-se a partir das experiências concretas que o indivíduo vivencia e, dessa forma, o sentido além de ser particular, é construído coletivamente. Desse ponto de vista, é possível supor que, a cada ano a mais de escolarização sob essa dinâmica e discursivizada do lugar de quem não aprende porque não se comporta, o sentido negativo que carrega de si própria vai se acumulando às experiências negativas com a escrita no ambiente escolar.

Nesse contexto, enquanto Júlia se cala e pouco participa, parecendo se conformar com a invisibilidade à qual foi relegada, Amanda ainda parece resistir, justamente tentando tornarse visível. Os enunciados expressos nos registros da escola aqui considerada denunciam, então, o assujeitamento dessas crianças do processo de apropriação da escrita, ao serem esvaziadas de suas singularidades, pois se distanciam tanto do padrão idealizado de alunos, quanto de aprendizagem, em meio a práticas pedagógicas também esvaziadas de significação para essas crianças, numa contínua naturalização do não apreender compreendido sob a lógica patologizante, não apenas por parte dos profissionais da saúde, mas também pela escola e seus professores.

Retomamos aqui os enunciados que orbitam sobre Júlia e Amanda acerca de como (não) aprendem e como (não) se comportam na escola. Júlia é retratada como tímida e pouco participativa, enquanto Amanda é agressiva e mal-humorada. Essas características individuais foram tratadas do lugar da desqualificação, sem espaço para reflexões sobre tais características. Particularmente no caso de Amanda, os enunciados foram se repetindo ano após ano, proferidos por profissionais da educação e da saúde, o que provavelmente se repetirá na trajetória educacional de Júlia, a depender da manutenção dessa cultura escolar aparentemente já enraizada nas práticas docente e pedagógica cotidianas.

\section{Considerações finais}

Compreender os sentidos sobre o não aprender discursivizados pela/na escola acerca das crianças aqui consideradas caracterizou o foco do presente artigo, na busca por evidenciar como tais sentidos são constituídos e produzem concepções e lugares de sujeitos. Dessa perspectiva, apresentamos elementos teóricos que remeteram à compreensão de escrita como atividade cultural complexa, sob a qual a escola e seus atores assumem fundamental relevância na proposição e realização de atividades pedagógicas que garantam protagonismo às crianças em processo formal de apropriação da escrita. 
Em igual medida, assumimos que a documentação pedagógica deve ser considerada como lócus de dialogia, portanto, lócus de interação e interlocução sobre os modos de ser e agir dessas crianças em sua relação com a escrita; ao mesmo tempo, como possibilidade discursiva de e entre profissionais da escola para dar visibilidade aos processos vividos, não como mero registro burocrático de informações descontextualizadas, mas como troca interlocutiva que possibilite aos profissionais da educação contribuírem, com seu trabalho educativo e científico, para a ampliação da inserção de cultura na escola e das crianças na cultura.

Estudos no âmbito da educação infantil demonstram outra forma de documentar os processos de aprendizagem das crianças, que se distancia desse formato de prestação de contas para as famílias e para a própria instituição. Isso desvela a importância de se pensar, também no ensino fundamental, que os documentos que acompanham o percurso da criança na escola precisam responder à ótica da documentação pedagógica como um instrumento vital para a criação de uma prática pedagógica reflexiva e democrática na construção de significados, em vez de sua utilização para a subjetivação dos discursos médicos pela educação sem uma potência informativa para compreender o processo e planejar ações futuras.

Buscamos discutir, ao evidenciarmos enunciados discursivizados sobre as duas crianças consideradas, tanto a naturalização dos sentidos do não aprender constituídos sob as tendências medicalizadora e patologizadora, sob as quais foram compreendidas em condição de assujeitamento da apropriação da escrita, quanto a falta de importância atribuída, pela escola, à documentação pedagógica, visto que não foi compreendida como possibilidade dialógica, mas utilizada como discurso institucionalmente legitimado por essa instituição. Ou seja, a documentação pedagógica não foi construída por ocasião do registro das narrativas sobre as crianças, mas por ocasião de sua utilização equivocada na legitimação de rótulos sob os quais as crianças têm sido continuamente aprisionadas e estigmatizadas.

Obviamente, não pretendemos com o presente artigo, generalizarmos a compreensão e utilização equivocadas da documentação pedagógica por parte de escolas e profissionais de educação, mas tomamos os dados aqui indiciados como um alerta, às escolas e seus profissionais, acerca das implicações e consequências dos modos como esses sentidos são discursivizados na escola e passam a ser determinantes na trajetória educacional das crianças, de modo geral, e das que são consideradas como as que não aprendem, aqui particularizadas. 


\section{REFERÊNCIAS}

BAKHTIN. M. Estética da criação verbal. São Paulo: Martins Fontes. 2011.

CHRISTOFARI, A. C. Modos de ser e de aprender na escola: medicalização (in) visível? Orientador: Cláudio Roberto Baptista. 2014. 173 f. Tese (Doutorado em Educação) Universidade Federal do Rio Grande do Sul, Porto Alegre, 2014.

COLLARES, C. A. L.; MOYSÉS, M. A. A. Preconceitos no cotidiano escolar: a medicalização do processo. In: Medicalização de crianças e adolescentes: conflitos silenciados pela redução de questões sociais a doença de indivíduos. Conselho Regional de Psicologia em São Paulo. São Paulo: Casa do Psicólogo, 2010.

COLLARES, C. A. L.; MOYSÉS, M. A. A. Medicalização: o obscurantismo reinventado. In: COLLARES, C. L.; MOYSÉS, M. A.; RIBEIRO, M. F. (Org..). Novas capturas, antigos diagnósticos na era dos transtornos. São Paulo: Mercado de Letras. 2013.

FREITAS, C. R.; BAPTISTA, C. R. Mais rápidas que a escola: crianças referidas como hiperativas no contexto escolar. Revista Ibero-Americana de Estudos em Educação, Araraquara, v. 14, n. esp. 1, p. 791-806, 2019. DOI:

https://doi.org/10.21723/riaee.v14iesp.1.12207

GARCIA, A. T. Como os processos de medicalização respondem às políticas públicas e avaliações externas: um olhar a partir do discurso de uma escola de alto IDEB. 2019. 116 f. Dissertação (Mestrado em Educação) - Universidade Estadual Paulista, Marília, 2019.

GERALDI, J. W. Portos de passagem. São Paulo: Martins Fontes, 2013.

GIROTO, C. R. M., ARAÚJO, L. A.; VITTA, F. C. F. Discursivização sobre “doenças do não aprender" no contexto educacional inclusivo: o que dizem os professores de educação infantil? Revista Ibero-Americana de Estudos em Educaçãa, Araraquara, v. 14, n. esp. 1, p. 807-825, 2019. DOI: https://doi.org/ 10.21723/riaee.v14iesp.1.12208

GUARRIDO, R. A Biologização da vida e algumas implicações do discurso médico sobre a educação. In: Medicalização de crianças e adolescentes: conflitos silenciados pela redução de questões sociais a doenças individuais. Conselho Regional de Psicologia; Grupo Interinstitucional Queixa Escolar. São Paulo: Casa do Psicólogo, 2010. p. 27 - 40.

MARQUES, J. B. Os sentidos do não aprender na perspectiva de alunos do ensino fundamental I, professores e familiares. Orientador: Claudia Regina Mosca Giroto. 2018. 158 f. Dissertação (Mestrado em Educação Escolar) - Universidade Estadual Paulista Araraquara, 2018.

MIOTELLO, V. Algumas anotações para pensar a questão do método em Bakhtin. In: GRUPO DE ESTUDOS DOS GÊNEROS DO DISCURSO - GEGe. Enfrentando questões de metodologia bakhtiniana. São Carlos, SP: Pedro \& João Editores, 2012.

PATTO, M. L. S. A produção do fracasso escolar: histórias de submissão e rebeldia. São Paulo: Casa do Psicólogo. 
PINAZZA, M. A.; FOCHI, P. S. Documentação pedagógica: observar, registrar e (re) criar significados. Revista Linhas, Florianópolis, v. 19, n. 40, p. 184-199, 2018.

SAVIANI, D. Pedagogia histórico-crítica: primeiras aproximações. São Paulo:

Cortez/Autores Associados, 1991.

SOLÀ, M. B. A arte do pintor de paisagens. Pátio Infantil, Porto Alegre, v. 4, n. 12, p. 40-42, 2007.

VIGOTSKI, L. S. A formação social da mente: o desenvolvimento dos processos psicológicos superiores. 7. ed. São Paulo: Martins Fontes. 2007.

VIGOTSKI, L. S. Aprendizagem e desenvolvimento intelectual na idade escolar. In: VIGOSTKY, L. S.; LURIA, A.; LEONTIEV, A. N. Linguagem, desenvolvimento e aprendizagem. 11. ed. São Paulo: Ícone, 2012. p. 103-116.

VOLÓCHINOV, V. Marxismo e filosofia da linguagem: problemas fundamentais do método sociológico na ciência da linguagem. Ensaio introdutório de Sheila Grillo. São Paulo: Editora 34, 2017.

\section{Como referenciar este artigo}

GIROTO, C. R. M.; MARQUES, J. N.; GARCIA, A. T. Medicalização da educação e os sentidos do não aprender discursivizados na documentação pedagógica: um olhar sobre o discurso da escola. Revista Ibero-Americana de Estudos em Educação, Araraquara, v. 15, n. esp. 5, p. 2932-2949, dez. 2020. e-ISSN: 1982-5587. DOI: https://doi.org/10.21723/riaee.v15iesp5.14567

Submetido em: 10/01/2020

Revisões requeridas em: 25/05/2020

Aprovado em: 30/10/2020

Publicado em: 01/12/2020 